\title{
Role of EU Grant Projects in Employment, Sectoral Employment and Innovation in Auto Repairing, Young Generations and New Horizons Project Case
}

\author{
Murat Çetin \\ Prof. Dr., Erzincan Binali Yıldırım University
}

\begin{abstract}
European Union Council Regulation (1085/2006 dated), the Financial Instrument for Pre-Accession (IPA) as well as for Turkey and potential candidate countries constitute the basis. The main objective of IPA is to assist the participating countries in dealing with European integration problems and undertaking the necessary reforms to comply with the Copenhagen criteria, which are EU membership requirements. Operation for Supporting Youth Employment in Sectoral Investment Areas (PYE-II) financed under IPA is carried out for employment, which is the primary target of its program. PYE-II operation, Turkish Employment Agency(ISSKUR) has been implemented in Turkey by and the overall goal is to promote youth employment, retain more people in employment and increase the employment rate of young people. In this framework, the aim of supporting Youth Employment in Sectoral Investment Areas is to increase the employability of young people while promoting their integration into the labor market. Within the scope of the Grant Program for Supporting Youth Employment in Sectoral Investment Areas (PYE II), innovations were realized in the Auto Repair, Young Generations and New Horizons project. In this study; Innovations in the professional activities of the Auto Repair, Young Generations and New Horizons project, their contribution to employment in the automotive repair industry and their effects were announced.
\end{abstract}

Keywords: EU Grants, Project, Vehicle Care, Youth, Employment

\section{Introduction}

The Council Regulation No. 1085/2006 constitutes the legal basis of Instrument for PreAccession Assistance (IPA) for Turkey as well as other candidate and potential candidate countries. The main objective of IPA is to help the beneficiary countries to face the challenges of European integration and to implement the reforms needed to fulfil the Copenhagen criteria for EU membership. In this respect, Human Resources Development is one of the components of IPA. The Human Resources Development Operational Programme (HRD OP) sets out the programming basis for receiving assistance from IPA funds in human resources development. The overall objective of HRD OP is "to support the transition to a knowledge-based economy capable of sustainable economic growth with more and better jobs and greater social cohesion". The HRD OP has four priority axes for adaptability by supporting employment, education, lifelong learning, and social inclusion (ikg.gov.tr, 2013). 
The EU contributes to youth employment in Turkey and provides employment programs to reduce the underlying problems in the labor market. Promoting Youth Employment in Sectoral Investment Areas financed under IPA the number one priority of the operation is to contribute to employment growth and continuity of employment. The main purpose of the program is to support and recruit more people by reducing youth unemployment and to employ them. These programs, which are implemented in line with the Council Regulation of the European Framework of Cooperation, aim to contribute to the creation of more and equal opportunities for young people, to increase the employment of young people, and to facilitate cooperation between relevant national. This program also aims local actors to facilitate the transition from College to work and to reduce the main problems of the youth in the labor market in Turkey (MLSS, 2013).

According to the results of the labor force survey in youth, while the unemployment rate was $20.8 \%$ in 2017 , it was $20.3 \%$ in 2018 . Unemployment rate for young men decreased by 0.2 points to $17.6 \%$ compared to the previous year and for young women this rate decreased by 0.8 points compared to the previous year and became $25.3 \%$. According to the results of the household labor force survey, when the employment rate of young people is examined compared to the previous year, in 2018 , the employment rate of youth increased by 0.7 points to $35 \%$. When youth employment is analyzed by gender; employment rate increased on 1 percentage point for young men to $46.4 \%$. Employment growth in young women increased on 0.4 points to $23.4 \%$. And $14.1 \%$ of working young men are employed in the agricultural sector, $36 \%$ in the industrial sector, and 49.9\% in the service sector. In March 2019, the share of employees without any social security institutions increased by 1.5 points compared to the same period of the previous year and became 33.9\%. The share of informal workers in the non-agricultural sector increased by 1.2 points to $23.1 \%$ compared to the same period of the previous year (TUİK, 2019).

This high level of youth unemployment is associated with a number of reasons that create a barrier to youth entry to the labor market. Among the most important economic, social, and institutional reasons leading to youth unemployment is the lack of holistic employment policies and services to support youth employment. Problems encountered in the transition from College to work (lack of a structural system to help young people find jobs in the transition from College to work, lack of work experience, etc.), incompatibility between inadequate job and vocational counseling services, investment/labor demand and vocational training are important factors. Insufficient information flow between universities and industry is due to insufficient guidance and counseling mechanism to support students, university graduates, and insufficient mechanism to provide information about job opportunities. The Program for Supporting Youth Employment in Sectoral Investment Areas (PYE II) Grant Scheme aims to contribute to the creation of a more employable youth population as a result of project trainings, and to reduce youth unemployment by focusing on the above mentioned problems. In addition, in order to contribute to the incentive system made under State Support in Investments on 06.04.2012, investment areas that will benefit from regional incentives were reviewed and supported to be revised on sectoral and provincial basis. It is highly ensured that the project proposals, which are of great importance for this call for proposals, are compatible with the new incentive system (ISSKUR, 2016). 


\section{Youth employment and vocational education programmes}

Turkey, with its young population is the country with an important human potential for a successful future. Turkey's young population, first, middle and higher education makes it mandatory regulations dealt with in a wide range of activities on the development of vocational education. On the basis of university-industry cooperation, the qualification of vocational education starting from the secondary education institutions is the first step and the labor force profile that the sector needs is shaped in the secondary education institutions. In today's vocational technical education, university-sector cooperation has an increasing prevalence due to the change in technological speed. According to the process of structuring these studies according to programs of participation process of the European Union, it is seen that the projects carried out in secondary education and university units produce studies on increasing quality and quantity in vocational technical education. These studies make university-industry collaboration in the region attractive and at the same time, the decision maker is actively involved in this cooperation as the relevant public institutions. Vocational Colleges are higher education institutions providing education and training with a two year associate degree aiming to raise qualified human power for specific professions to meet the sectoral needs. In education vocational, the vocational colleges that educate human power have a more conscious basis. Therefore, vocational education in vocational colleges plays an important role in the secondary education of their students, and more importantly, beyond the vocational education, the point of view of life, communication and interaction with the environment is gaining importance. In vocational colleges, theoretical knowledge of education is given a large amount of practical training and the integration of the students with the students and finally the employment compatible with the profession is realized. In addition, the university plays a locomotive role in determining the quality of the labor force needed by the sectors in such training programs. Vocational Schools are the most important educational institutions that provide the necessary qualified intermediate staff. Graduated students are employed as qualified midterm personnel between engineers or specialists and workers in the sector with the title of Technician and Professional Personnel. The main objective of the vocational colleges is to educate the skilled intermediate human power which is the necessity of the industry and the service sector for the professions. However, vocational colleges also have the aim of producing information through scientific research, disseminating information, transforming it into knowledge product and technology. Vocational training is defined as the type of training that gives individuals knowledge, skills and work habits related to a particular occupation in their work life and develops their skills in various aspects. Vocational education is the result of educational activities that enable an individual to demonstrate his qualitative power and functioning according to the economic conditions of that country in each country. The main objective of vocational training is to meet the demands of the labor force and qualified labor force demanded by the sectoral sectors. In this sense, vocational and technical education; It is a process which gives knowledge, skills and attitudes related to a certain profession area to meet the needs of society and individuals and which enables the individual to become stronger in social and economical direction by developing his abilities. Vocational training aims at defining individuals as a profession in industry, agriculture, commerce and other service areas, in the development of the profession, in the system integrality of the principles to be applied in the formal, widespread and apprenticeship training for occupational change (Alkan et al.,1996; Republic of Turkey Official Gazette 1981). Vocational high colleges that provide associate degree education in our universities can also contribute to the unemployment of the unemployed by applying vocational education programs. It is seen 
that educational institutions can combat unemployment by implementing vocational trainings that will provide the development of the required qualified and skilled workforce, the sectoral technological change and development needed. As a side effect of these trainings, these training programs also complete their technological innovations by following the technological innovations very well. One of the most important sources of these technological innovations is the EU grant projects that provide financial support.

\section{EU Grant Projects and Sector Cooperation}

European union; It establishes partnerships with countries that share the same core values as democracy, human rights and the market economy, and contributes financially to the economic and social development of the countries concerned through various financial instruments. These are the countries that are candidates for EU membership or are in the process of membership. Since the countries involved in this process are considered candidate countries, they receive financial support under the pre-accession assistance (IPA) problem. The grant programs provide the opportunity to develop and participate in projects for their own needs, while also enhancing the participation and capacity of institutions in these countries. These institutions receiving financial support from the EU; it contributes to the design and implementation of public policies in various fields such as health, vocational education, technological infrastructure and rural development (IPA, 2013). Projects supported by various sources; These are policy tools that enable better definition of needs, adaptation to national priorities, improvement of participatory planning, top-down development of the planning concept, development of local partnerships and collaborations, and increased project capacity and transparency. Also such projects; Increases transparency as it includes stages such as qualified competition, quality, selection criteria, independent evaluation and public announcement of the winners. On the other hand, it contributes to accountability by clearly showing the duties and responsibilities of the staff at every stage during the project in laws such as participant, interrogator and cooperation. As a result of the increase of such grant projects and the development of project awareness, it contributes to the recognition of the EU by the society, the reduction and elimination of prejudices. At the same time, the activities of the grant projects contribute to the economic growth of the target audience and the positive impact of the secondary stakeholders. The projects contribute to the development of human capital, the increase of the educated workforce who can use and access modern technologies. With such projects, social awareness is created to compete and improve in institutions and therefore individuals, and sectoral employment growth is supported. In particular, vocational education projects ensure the sustainability of employment by improving the level of human capital, strengthening the level of employment of individuals who have acquired knowledge and equipment. Projects support and strengthen local and regional priorities, resource need in the region, and the feasibility of relevant plans and policies. Ensuring the success and sustainability of the projects will increase the business vitality and new business investments of the project beneficiaries by establishing business in business expansion or indirect beneficiaries, increasing entrepreneurship and competitive quality. Today, due to the rapid change in the world, countries are struggling in the fields of education, health and economy to increase their welfare levels. At the center of this struggle is the ideal of a highly educated society that produces development-based knowledge and technology. In addition to student education, universities also carry out research and development activities to produce the education and training activities and information needed by the region. Universities for the high welfare of the society; They carry out the 
mission of producing information, having information, renewing existing information and transforming new information into new technological products. Sectoral structures diversified by their fields of study, small and medium-sized enterprises (SMEs) are of great importance in all countries, and increasing employment in small and medium-sized enterprises, especially at local and regional level, is important in our country. They can contribute to the creation of the scientific infrastructure of the sectors by conducting applied research at local level with institutions such as Universities, Chambers of Commerce, Chambers of Industry and Craftsmen. As a result of the cooperation of the universities with the institutions, implementing concrete projects with the potential project partners and realized projects are of great importance. Universities have the potential to generate social and economic value by project outputs at the academic level and by using them in the commercial field or by forming the basis of other projects. Projects carried out with grant programs have features that can raise awareness to support regional policy instruments or existing instruments as a mechanism. Capacity building with EU grant-aided development programs and regional projects coordinated by different ministries has strengthened to include all local actors. Projects; While it provides opportunities to modernize equipment and equipment for both schools and sectors in all areas of the economy in our country, it also contributes to vocational education needs by using new technologies (Çetin, Orman, 2009).

\section{Innovation in Auto Repairing, Young Generations And New Horizons Project in Erzincan}

This project was carried out under the "Youth Employment Support Grant Program in the European Union's Sectoral Investment Areas" implemented by the Ministry of Labor and Social Security. Under this title, Innovations, Young Generations and New Horizons in Auto Repair were realized in Erzincan city center within 12 months. Erzincan, located in the Eastern Anatolian region, has a population of 159.589 in the central district and 231.511 in 8 districts (TÜIK, 2018). The overall purpose of the project; According to the active labor market targets, it is to reduce the youth unemployment rate by providing the employment of young people in the field of repairing motor vehicles with potential for growth in Erzincan. The special purpose of the project is to cooperate with the automotive sector, which is one of the active labor market priorities, to complete the professional development of young employees in the sectors and to ensure the continuity of the employment of young people working. In addition, the project aimed to enable unemployed youth to become qualified professionals through vocational training and to reach an education level where they can start a business by developing entrepreneurship training and entrepreneurship skills. It is aimed to direct young people to work life with their professional training, to create a culture of cooperation between universities and industry sectors, and to accelerate the transition from school to employment through internship practices. As part of this mission, the university includes a range of vocational training and development programs that will set an example for sustainable development and knowledge for trade partners, industrialists, tradesmen, unemployed young women and men who want to improve their jobs. Innovations in Auto Repair, Young Generations and New Horizons Project; It has a feature that includes youth employability, youth entrepreneurship skills, sustainable cooperation, youth employment profiling, orientation, education, consultancy, work experience, transition from school to work and all activities that will establish a stronger link between university and industry. Project; one of the main target groups of the call for proposals; The aim of the unemployed youth who are university graduates, high school graduates, low education, dropping out of school and not continuing their education is aimed to be brought to the Auto Repair sector. Young people with 
a project target group are trained on the basis of the Automotive (Production, repair and maintenance etc.) sector, which is among the sectors were built under the New Incentive System. During the implementation of this project and in the coming years, there is a consensus on ensuring that all necessary information and sharing is necessary to ensure the development of activities aimed at increasing youth employment and entrepreneurship by creating synergies with the common and complementary activities

According to Erzincan Chamber of Auto Repairers 2017, there are 365 workplaces that perform maintenance and repair of motor vehicles and 745 people work in the sector. Among these establishments, 270 workplaces carry out maintenance and repair of motor vehicles, 42 workplaces auto bodywork, 45 workplaces auto paint works and 13 workplaces sell auto parts. Depending on the growth of business volume in the sector, it creates an opportunity for the employment of young generations with vocational training in the sector. Generally, the owners of the workplace are over 45-50 years old and have mastered the traditional apprentice method without any professional technical training and have difficulty in using the technological test devices. mechanic shopkeepers cannot adapt to the rapid developments in the automotive industry. For these reasons, since vehicle owners prefer to get service from authorized services for their services, this reduces the competitiveness of existing auto repairers. For this reason, it is estimated that this problem will be solved by the employment of young generations capable of using computer controlled devices as a qualified staff as a result of vocational training. Engine vehicles; are basic pollutants and their negative impact on environmental-air quality is constantly increasing. On the other hand; the use of trained human factor, motor vehicles, test and adjustment devices play an important role in reducing the effects of motor vehicle-centered pollutant emissions on environmental pollution. Modernization of auto mechanic tradesmen in Erzincan is due to the strengthening of tradesmen through vocational trainings and the training of young generations who have the ability to use new technologies. According to the statements of business owners; with the new change process, it means that $1 / 3$ of the existing 365 workplaces can be employed and 132 new jobs can be created in the sector. This means an increase in employment in the sector around $17 \%$, and it is estimated that the employment of trainees participating in the project training in the field of auto repair will increase by approximately $10 \%$. As a result of the project activities, young craftsmen with high speed to adapt to the changes in motor vehicles that are in a great change will become qualified in the coming years, the auto repair shop trades become qualified. Considering that the total number of vehicles in Erzincan is 60.084 according to 2018 data, there is a continuous increase in the number of vehicles in the sector and therefore the number of customers. The increase in the number of vehicles in our city can be considered as an indicator of the need for qualified personnel for employment. The motor vehicle industry is in a very rapid technological change, and this rapid change has also changed the maintenance, repair, replacement and spare parts industry of the systems that make up the motor vehicle. Considering that a standard equipped car consists of approximately 10.000 parts, it is seen that the classical service concept and repair processes are no longer valid. The increase in vehicle and model diversity also increased the variety of spare parts used by the industry. For this reason, quality spare parts supply, demand, spare parts order, storage classification, regulation of spare parts entry and exit inventory bring a great workload. Since spare parts storage is filled with a huge financial burden for auto repairers, supply of spare parts depending on the job demand is needed in the sector. With this application, the repair shops will be institutionalized and the unrecorded financial losses will be prevented as the supply and sale of spare parts will be recorded. 


\section{Features of the Project Target Groups and Training Activities}

Within the project target group; There are 25 vocational school graduates or students, 15 young people over the age of 15, 15 young people who can receive apprenticeship training, 15 young people working as apprentices in automotive repair shops, and 20 high school or equivalent graduates. As Project Training Activities;

1. Entrepreneurship training (72 hours),

2. On-the-job and career counseling training (28 hours),

3. Automotive Electromechanics vocational training ( 400 hours),

4. Automotive Body Painting and Painting Professional training (400 hours),

5. Auto Spare Parts Sales Staff training (384 hours),

6. Industrial internship training (160 hours / 1 month)

7. Seminars and conferences (6),

8. Sector technical examination trips (2) were made.

75 young people with different educational levels between the ages of 15-29 were identified for 3 different education programs. 68 youngsters from the project trainees completed their project training. Within the scope of the project, they have become ready for employment as employees who have sufficient equipment for employment in the sector as vocational training in 3 different modules and qualified vehicle in motor vehicle repair. As part of the project trainings, 68 young people received 72 hours of Entrepreneurship and 28 hours of Job and Career Counseling training. Automotive Electromechanics professional training; engine repair, which is a separate profession in classical auto repair, has become a whole by combining with electricity and auto electronics. In this module, a total of 400 hours is planned as vocational lessons, 8 hours per day, and 50 workdays received vocational training, and 22 young people completed the electromechanical training of motor vehicles. Automotive Body Painting and Automotive Painting Vocational Training; due to the changes in the motor vehicle industry, auto body and auto paint technologies have also turned into an integrated structure. In our project, the second profession group has been described as a training program in which Auto Body and Auto Paint technologies are explained as a whole and as a module consisting of a total of 400 hours of lessons. It is planned as 8 hours daily and 24 young people completed 50 vocational training. Auto Spare Parts Sales Staff training; since the rapid change in the sector, vehicle and model diversity has rapidly changed the auto spare parts diversity, it has become a specialization. It shows that trained personnel are needed to employ personnel in this field in the sector. For this purpose, our project aimed to employability of 25 young high school and vocational high school graduates in this field. Considering the training module, a total of 384 hours, 8 hours a day, and 48 working days of vocational training have been provided, 21 young ( 9 female) trainees have been successfully completed. At the end of vocational training, trainees completed 160 hours internship trainings in 1 month at the workplaces that are members of the Chamber of Repairers and the authorized vehicle sales and service companies in Erzincan city. Entrepreneurship Office and Career Counseling Center, one of the Project activities within the university, was established and career counseling services were provided to 255 Vocational School students in the 2016-2017 academic year and the center has been operating for 3 years. 


\section{Employment Level of the Project and Sector Impact}

Project; General Skills Trainings, Guidance and Counseling, Vocational Training, Entrepreneurship Trainings included activities suitable for the transition from school to business life. The Entrepreneurship Office and Career Counseling Center, which was established as a project activity within the Erzincan Vocational School. The Entrepreneurship Office and Career Counseling Center continued its entrepreneurship, vocational guidance and career training, while also monitoring the employment and success performances of the project trainees in the labor market until the end of 2019 for 3 years. As of July 2019, the number of trainees in employment is 16 and the institutions they are employed with are given in the table below. Very few women work in the workplaces on the Auto Repairers site. It is aimed to increase the number of female employees, especially in working environments in offices and offices. For this purpose; 9 young ladies, who graduated from Vocational School of Vocational Education in Auto Spare Parts Sales, participated in the trainings and 6 young female trainees were employed at the end of the project. If the project reaches the desired level of success and recognition, it is thought that it will bring other activities to the agenda and set an example in Erzincan.

\section{Results And Evaluation}

With this project implemented within the scope of "Supporting Youth Employment in Sectoral Investment Areas", the work capacity, professional knowledge and work quality of auto repairers have been contributed. In the automotive service and repair industry; economic development, competition, environmental protection awareness, the idea of organizing a workplace under favorable conditions and its contribution to improving the quality of life of the society will continue in the coming years.

- As a result of the success of the youth working in the sector, the young target audience consisting of auto repairers contributes to the development of human resources, while the risk of losing jobs in the sector will decrease.

- An auto mechanic tradesman who moved to the new industrial site and aimed at expanding his business capacity, therefore, assuming that business growth would be realized with qualified young employees, was provided with opportunities for employment and 16 trainees were registered in the sector.

-It is estimated that at least half of the trainees will be employed in the sector in Erzincan and other provinces within the next 5 years.

- In the auto repair sector, there has been a development in the areas of sustainability and sustainability of the effects of success as a result of the training activities of motor vehicle test and adjustment devices, competition.

-As a result of the project trainings, the spirit of entrepreneurship, the importance of transition to formal employment and the development of environmental awareness were observed in the young target group.

-As a other of the project results, with the increase in employment of young people in auto repair, the development of human resources, improvement of the quality of education and the development of professional knowledge in auto repairers have been provided. 
- Besides the trained workforce who can use modern and technological test devices in auto repair with project results, it will trigger the target audience in terms of competitiveness and development of its business.

Thank; this research, the contracting authority: Repiblic of Turkey Ministry of Labor and Social Security - European Union Coordination Department, Human Resources Development Operational Program IPA Component IV. As a result of Innovations, Young Generations and New Horizons in Auto Repair, by Erzincan Binali Ylldırım University. The author (project coordinator), for his contribution to the study; European Union Delegation to Turkey, the Ministry of Labor and Social Security Coordination Department of the European Union, Turkey would like to thank the Employment Agency.

\section{References}

[1] http://www.ikg.gov.tr, 2013- IPA and HRD OP.Ankara/Turkey.

[2] Ministry of Labour and Social Security, MLSS, 2013- European Union Coordination Department Promoting Registered Employment II., Grant Scheme, Guidelines for grant applicants., Ankara.

[3] Turkey Statistical Agency(TUIK), 2019,- Newsletter(Turkish)., Ankara.

[4] Turkey Business Association(İŞKUR).,2016,-World Labor Market. 8th General Assembly Working Paper(Turkish)., Ankara.

[5] Alkan Cevat,Doğan hıfzı., 1996,- Principles of Vocational Technical Education(Turkish). Gazi Büro Kitabevi. Ankara.

[6] Republic of Turkey Official Gazette.,1981-Higher Education Law(Turkish), dated 04/11/1981 and numbered 17506.

[7] http://ec.europa.eu/regional policy/en/funding/ipa/).,2013,-Pre-Accession Assistance (IPA).

[8] Çetin Murat, Orman Kamil., 2009 -Erzincan Reflections of EU Grant Projects and Looking to the Future, International Congress on Intercultural Dialogue and Education., Bursa.

[9] Turkey Statistical Agency(TUIK), 2018 -Provincial Population Report (Turkish)., Ankara. 